\title{
Platelet Adhesion to Collagen Type I, Collagen Type IV, von Willebrand Factor, Fibronectin, Laminin and Fibrinogen: Rapid Kinetics under Shear
}

\author{
Renata Polanowska-Grabowska, Carl G. Simon, J r., Adrian R. L Gear \\ From the Department of Biochemistry, University of Virginia, Charlottesville, VA, USA
}

\section{Summary}

Extracellular matrix proteins in the blood vessel wall fulfill an essential role in haemostasis by promoting platelet adhesion at the site of vessel injury. We have combined a continuous-flow system with affinity chromatography to study platelet adhesion under conditions mimicking arterial flow and have examined the adhesion kinetics of unstimulated platelets to collagens type I and IV, von Willebrand factor (vWf), fibronectin, laminin and to fibrinogen. In the absence of red cells, in ACD-prepared plasma adhesion to collagens type I and IV or vWf was rapid, efficient $(>50 \%$ in $<1 \mathrm{~s})$ and independent of shear rates from 650 to $3400 \mathrm{~s}^{-1}$ with kinetics following an inverse exponential decay curve. We introduced a simple mathematical model in which this type of kinetics arises, and which may be more generally applicable to various adhesion processes under flow conditions. The model is characterized by the rate of platelet deposition on the adhesive surface being proportional to the number of platelets in the flow. Adhesion to fibronectin was independent of shear rate, but revealed a lag phase of $\sim 1.5 \mathrm{~s}$ before significant adhesion began. Laminin and fibrinogen supported efficient adhesion at low shear rates $\left(650-1000 \mathrm{~s}^{-1}\right)$, but a lag phase of $\sim 1.5 \mathrm{~s}$ was seen at high shear rates $\left(1700-3400 \mathrm{~s}^{-1}\right)$. Control proteins (albumin and gelatin) supported minimal adhesion. Nonspecific adhesion to poly-1 -lysine differed from that to other substrate proteins in that the kinetics were linear. In conclusion, human platelets adhered specifically, rapidly (within seconds) and efficiently to several proteins under flow conditions and the kinetics of adhesion depended on the protein serving as substrate as well as on shear rate.

\section{Introduction}

Adhesion of blood platelets to exposed subendothelial tissue following vascular injury is a crucial part of the initial events of haemostasis $(1,2)$. Platelet adhesion to proteins in this tissue must be nearly instantaneous as shown by calculations indicating that reaction times as short as $10 \mathrm{~ms}$ are required to support efficient haemostasis in the arterial circulation $(3,4)$. Many factors impact the speed and efficiency of platelet adhesion to the subendothelium. First, platelets do not adhere equally well to all substrates. In addition, the location of the injury in the vascular tree influences adhesion since the composition of subendothelial tissue as well as shear rates experienced during blood flow vary with respect to the location of the lesion (5-9). Finally, the extent and depth of the vessel wall lesion will affect which extracellular

Correspondence to: Dr. R. Polanowska-Grabowska, Department of Biochemistry, University of Virginia, Box 440, Charlottesville, VA 22908, USA Tel.: +1 804 924-2387; FAX: +1 804 924-5069; e-mail: rp4t@ virginia.edu matrix (ECM) proteins become exposed, as well as alter local shear rates, thereby influencing the efficiency of platelet adhesion.

Many ECM proteins found in the vessel wall, including different collagens types I, II, III, IV, VI and VIII, von Willebrand factor (vWf), fibronectin, laminin, thrombospondin and vitronectin, can support platelet adhesion (10). Collagen is particularly important since it is a main structural component of the vessel wall and directly activates platelets (11). In contrast to collagen which is found in the vessel wall but not in plasma, some adhesive proteins, such as vWf, fibronectin, vitronectin, and fibrinogen, are present in plasma and in platelet $\alpha$-granules. Fibrinogen can also be found incorporated into a clot. The platelet adhesion to collagen has been extensively studied $(10,11)$. It has been shown that under flow conditions adhesion to collagens types I, II, III and IV is independent of shear rate above $300 \mathrm{~s}^{-1}$ (12). In contrast vWf has been reported to mediate platelet adhesion to the subendothelium at high shear rates $\left(>800 \mathrm{~s}^{-1}\right)(13)$, while fibronectin and laminin support adhesion under static conditions $(14,15)$ and low shear rates $\left(<1000 \mathrm{~s}^{-1}\right)(16,17)$. Similarly, fibrinogen when immobilized on plastic or incorporated as insoluble fibrin in clots, promotes efficient adhesion under static conditions and low shear rate $\left(\sim 275 \mathrm{~s}^{-1}\right)$ (18-20).

Thus, it has been well established that several proteins of the subendothelium can support platelet adhesion. Most of these studies were performed on a timescale of minutes or hours under static or flow conditions. However, evidence for the rapid platelet adhesion (seconds) needed for efficient haemostasis is scant. Previously, by combining a continuous-flow approach with a micro-affinity column, we have shown that human platelets can rapidly adhere to immobilized collagen type I after exposure times as short as $130 \mathrm{~ms}$ (21). Further, changes in levels of cyclic nucleotides (22), in protein phosphorylation (23), and dissociation of a complex of heat-shock proteins and protein phosphatase 1 (24) have been observed within $90 \mathrm{~s}$ of this rapid adhesion to collagen. In the present study, we have examined the ability of platelets to adhere rapidly to several ECM proteins (collagens type I and IV, vWf, fibronectin, laminin) and to fibrinogen. We have shown that all of these proteins are able to support efficient platelet adhesion within several seconds under flow conditions similar to those in micro-circulation.

\section{Materials and Methods}

Materials

Sepharose 4B, fibrinogen from human plasma, collagen type IV from human placenta, gelatin type B from bovine skin, poly-l -lysine bound to $\mathrm{CNBr}$ activated Sepharose 4B beads, fatty acid-free bovine serum albumin (BSA) and other specialty chemicals used were obtained from Sigma (St. Louis, MO). Fibronectin was prepared from human plasma by using a gelatin-affinity column (25). Von Willebrand factor (vWf) from human plasma (26) was a gift 
Table 1 The initial rates of platelet adhesion

\begin{tabular}{|c|c|c|}
\hline Protein & Initial rate $(\% / \mathrm{sec})$ & $( \pm) \mathrm{SE}$ \\
\hline BSA & 6.4 & 0.3 \\
\hline Gelatin & 10.3 & 2.1 \\
\hline Poly-1 -Lysine & 15.9 & 0.3 \\
\hline Collagen Type I & 83.1 & 5.6 \\
\hline Collagen Type IV & 103.9 & 2.1 \\
\hline vWF & 62.4 & 2.6 \\
\hline Fibronectin & 8.6 & 1.8 \\
\hline \multirow[t]{2}{*}{ Laminin } & 2.8 & 1.1 \\
\hline & 19.1 & 4.9 \\
\hline \multirow[t]{2}{*}{ Fibrinogen } & 11.8 & 2.1 \\
\hline & 26.9 & 0.1 \\
\hline
\end{tabular}

The initial rates were determined from the slopes of the adhesion plots presented in Fig. 1 by linear regression analysis. The slopes were calculated from the first three data points (including time zero). "High" refers to shear rates of $1700-3400 \mathrm{~s}^{-1}$ and "Low" corresponds to shear rates of $650-1000 \mathrm{~s}^{-1}$. Results are expressed as means \pm SE of values from 4 experiments (each done in duplicate) and presented as percent of adhering platelets per second $(\% / \mathrm{s})$.

from Dr. Z. M. Ruggeri (The Scripps Research Institute, La Jolla, CA). Laminin type I from mouse tumors (27) was a gift from Dr. R. Ogle (University of Virginia, Charlottesville, VA). Native, soluble collagen type I from rat skin was a gift from Dr. G. Balian (University of Virginia, Charlottesville, VA). Purity of the proteins before coupling to beads was $>95 \%$ as revealed by SDSpolyacrylamide gel electrophoresis.

\section{Protein-coupling to Beads}

Type I collagen, fibronectin, gelatin, type I laminin, vWf, fibrinogen, or BSA were dissolved at $1 \mathrm{mg} / \mathrm{ml}$ in $0.1 \mathrm{M} \mathrm{NaHCO}_{3}(\mathrm{pH} 8.3$ ) containing $0.5 \mathrm{M}$ $\mathrm{NaCl}$, dialyzed in this buffer for 2 days at $4^{\circ} \mathrm{C}$ and coupled in this buffer to CNBr-activated Sepharose 4B as described (28). Type IV collagen $(1 \mathrm{mg} / \mathrm{ml})$ was dissolved in $0.1 \mathrm{~N}$ acetic acid ( $\mathrm{pH} 3.0$ ), dialyzed against $0.1 \mathrm{M}$ calcium acetate buffer ( $\mathrm{pH} 8.8$ ) for $24 \mathrm{~h}$ at $4^{\circ} \mathrm{C}$ and coupled in this buffer to $\mathrm{CNBr}$ activated Sepharose 4B as described (28). Efficiency of coupling for each protein was $>50 \%$ as determined by measuring protein absorbance of the supernatants after coupling compared to protein solutions before coupling (29).

\section{Platelet Preparation}

Human venous blood was anticoagulated with acid-citrate-dextrose (ACD) to a final citrate concentration of $11.5 \mathrm{mM}$ in whole blood and centrifuged at $350 \mathrm{~g}$, twice for 3 and once for $5 \mathrm{~min}$, all at room temperature as described (30). Platelet rich plasma (PRP) was removed after each centrifugation step and final platelet concentrations were $4-6 \times 10^{8}$ platelets per ml. All donors gave informed consent and denied having taken medications such as aspirin before giving blood.

\section{Adhesion Assay}

The adhesion assay is based on a quenched-flow method (30) and was performed as described (21). PRP and isotonic saline pre-warmed for $5 \mathrm{~min}$ at $37^{\circ} \mathrm{C}$ were pumped through a micro-column $(150 \mu \mathrm{l}$ capacity, $1 \mathrm{~mm}$ internal dia.) of 15-100 $\mu$ l of loosely-packed protein-coated Sepharose beads using a syringe pump. Flow rates through the column were varied from 1.3 to $6.7 \mu \mathrm{l} / \mathrm{s}$, giving a range of shear rates of 650-3400 $\mathrm{s}^{-1}$ and a range of contact (adhesion) times of $0.2-6.0 \mathrm{~s}$. Percent of adhesion was determined by counting the percentage loss of single platelets measured by resistive-particle counting before and after exposure to the beads. The initial rates of adhesion (\%/s) were determined from the plots in Fig.1 by calculating the slope of a line that was fit to the first three data points (including time zero) of each plot by linear regression (Table 1).

\section{Calculation of Shear Rates}

The column of protein-coated beads has been treated as a porous medium, and the approximate average shear rate $\gamma\left(\mathrm{s}^{-1}\right)$ at the surface of the beads has been computed from the formula $\gamma=4 \mathrm{Q} / \pi \mathrm{N}\left(\mathrm{r}_{\mathrm{p}}\right)^{3}$ where $\mathrm{Q}$ is the flow rate, $\mathrm{N}$ is a number of pores, and $\mathrm{r}_{\mathrm{p}}$ is the radius of a pore as described (21). For pumping rates of 6.7 and $1.3 \mu \mathrm{l} / \mathrm{s}$, calculated shear rates were 3400 and $650 \mathrm{~s}^{-1}$, respectively.

\section{Results}

Platelet adhesion to collagen type I, collagen type IV, vWf, fibronectin, fibrinogen, or laminin-coated beads was assessed by pumping resting platelets over a microcolumn of the beads under conditions mimicking arterial flow. Percent adhesion was determined from the number of single platelets that eluted from the column (Fig. 1) and initial rates of adhesion $(\% / \mathrm{s})$ are shown in Table 1.

Collagen type I, collagen type IV and vWf were the most efficient adhesive substrates. Adhesion to these proteins reached 50\% in less than a second and was independent of shear rate over the range $650-3400 \mathrm{~s}^{-1}$ (Fig. 1D-F). By applying linear regression analysis to the logarithmic plots of adhesion kinetics for these 3 proteins as in (21), we found that they followed inverse exponential decay curves. These curves can be described by the formula: $a(t)=1-\exp (-t / \tau)$, where $a(t)$ is the adhesion rate at time $t$, and $\tau(\mathrm{s})$ is the time constant characterizing the speed of adhesion. The time constants obtained by this method for the kinetics presented in Fig. 1D-F for collagen type I, collagen type IV and $\mathrm{vWf}$ were $\tau=1.2 \pm 0.1 \mathrm{~s}, \tau=0.90 \pm 0.07 \mathrm{~s}$, and $\tau=1.5 \pm 0.1 \mathrm{~s}$, respectively. Adhesion to fibronectin, laminin, and fibrinogen did not follow the inverse exponential decay, but had a sigmoidal pattern (Fig. $1 \mathrm{G}-\mathrm{I}$ ). Adhesion to fibronectin was independent of shear rate, but there was a lag time of $\sim 1.5 \mathrm{~s}$ before adhesion became efficient (Fig. 1G). In contrast, adhesion to laminin and fibrinogen was dependent on shear rate. At high shear rates (1700-3400 s-1) a lag phase $(\sim 1.5 \mathrm{~s})$ was evident, which vanished at lower shear rates $\left(650-1000 \mathrm{~s}^{-1}\right)$ (Fig. $1 \mathrm{H}, \mathrm{I})$.

Initial rates of adhesion derived from linear regression analysis of the first three data points from plots in Fig. 1 clearly reveal the existence of a slow lag phase for adhesion to laminin and fibrinogen under high shear rates (Table 1) and for adhesion to fibronectin independent of shear rate. The initial rates of single platelets adhering per second (mean \pm SE, for 4 independent experiments) for collagen type I, collagen type IV and vWf were 83.1 \pm 5.6, $103.9 \pm 2.1$, and $62.4 \pm 2.6$, respectively. These rates are actually greater than seen for maximal rates of platelet aggregation induced by thrombin or ADP (30), and closely approach those needed for efficient haemostasis in the arterial circulation.

To establish that platelet adhesion was specific, we tested adhesion to the control proteins, albumin, gelatin (boiled collagen) and to poly1 -lysine. Adhesion to albumin $(<7 \%)$ or gelatin $(<15 \%)$ was minimal at all contact times regardless of shear rate $\left(650-3400 \mathrm{~s}^{-1}\right)$ (Fig. 1A, B). Platelets nonspecifically adhered to poly-1-lysine in shear rate independent manner and the kinetics were slower and discernibly different from the adhesion characteristics observed with other substrate proteins (Fig. 1C). Adhesion to poly-l -lysine was linear for exposure times through $2.5 \mathrm{~s}$. Platelet adhesion to fibronectin, laminin, and fibrinogen was less efficient than adhesion to the collagens and vWf, but was more efficient than adhesion to the control proteins, albumin, gelatin and poly-l -lysine. 
A

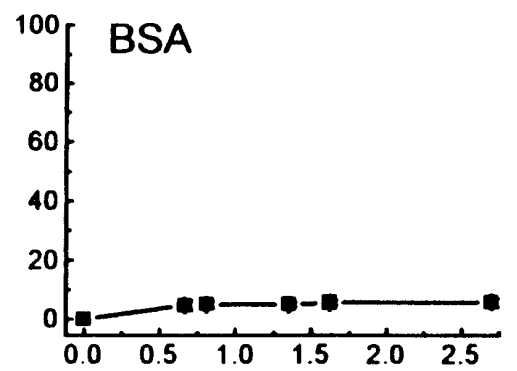

D

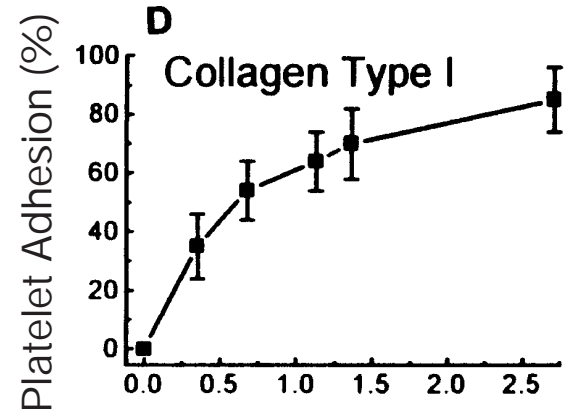

G

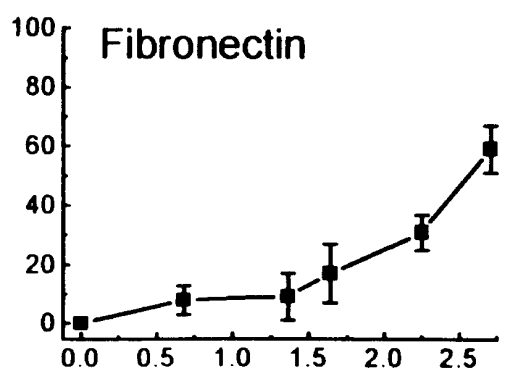

B

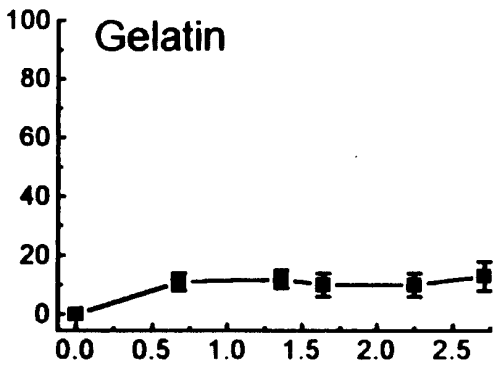

E

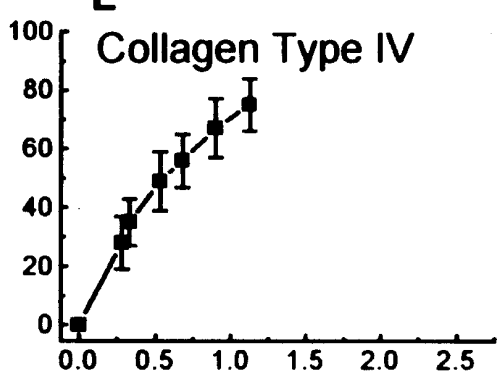

H

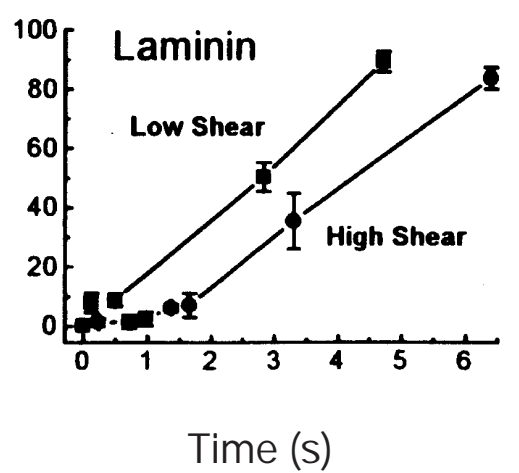

C

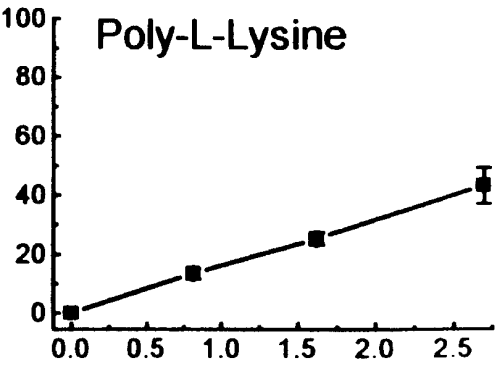

$F$

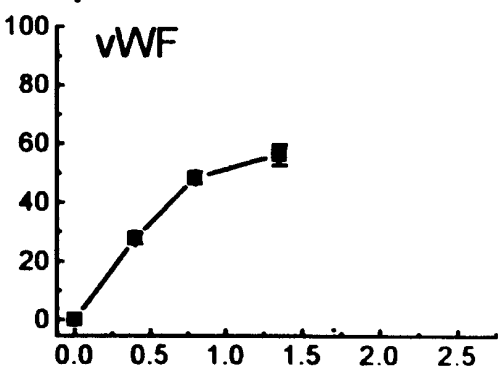

I

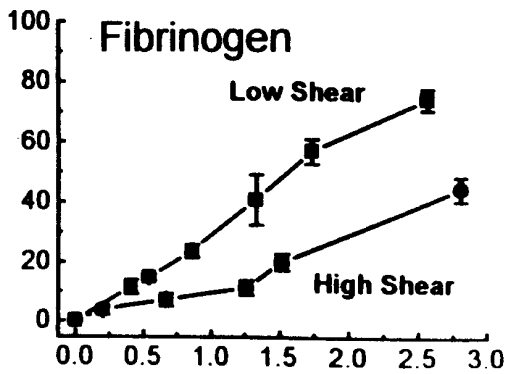

Fig. 1 Kinetics of platelet adhesion to various proteins. Platelet adhesion to various proteins was determined using a flow-through, microadhesion column (21). Platelets were pumped over a microcolumn of protein-coated beads and percent adhesion was determined by counting the number of platelets remaining in the effluent. Percent adhesion is indicated on the y-axis while time of exposure (contact time) is expressed on the x-axis. Adhesion to BSA, gelatin, poly-l -lysine, collagen type I, collagen type IV, vWF, and fibronectin was independent of shear rates over the range 650-3400 $\mathrm{s}^{-1}$. Adhesion to laminin and fibrinogen was dependent on shear rates and in those two plots "Low Shear" corresponds to shear rates of 650-1000 s $\mathrm{s}^{-1}$ and "High Shear" refers to shear rates of 1700-3400 s"Note that the time-axes are the same for all of the plots except laminin and fibrinogen. The data are expressed as means of four separate experiments (each done in duplicate) and error bars represent \pm SD

\section{Disc ussion}

Since adhesion at sites of vascular injury must occur in seconds in order to ensure efficient haemostasis in the arterial circulation $(2,4)$, we have used a flow-through microaffinity column to determine how rapidly and efficiently platelets can adhere to ECM proteins and to fibrinogen on this timescale. We found that platelets in ACD-prepared plasma were able to adhere efficiently ( $>50 \%$ ) and fast (within seconds) to collagens type I and type IV, vWf, fibronectin, laminin and fibrinogen (Fig. 1D-I). Platelet adhesion occurred without prior stimulation by soluble agonists such as thrombin, ADP, or epinephrine, indicating that resting, circulating platelets have an inherent ability to bind efficiently to each of these proteins.

Many studies have examined the ability of platelets to adhere to substrate proteins using a variety of adhesion assays that often take minutes or hours $(11,13,15,17,18,20)$. The present approach has two clear advantages with respect to these reports. First, our continuousflow assay shows that platelets can adhere to substrate proteins after very short exposures, as little as $130 \mathrm{~ms}$ (21). Second, we have used a single assay to examine platelet adhesion to a number of substrate proteins, allowing comparison of the adhesion kinetics. We coupled all of the proteins to Sepharose beads similarly (by using the same concentrations of proteins in solution for binding to $\mathrm{CNBr}$-activated Sepharose 4B ), used the same assay for evaluating adhesion (flowthrough microaffinity column), and prepared the platelets in the same way. The various adhesion assays and platelet preparations that have been used to study platelet adhesion in different reports has made direct comparison of results difficult.

The continuous-flow microadhesion assay differs in two important aspects from other techniques used to study platelet adhesion under flow conditions. The geometry of the platelet flow through the tightly packed protein coated beads is complex and there are no red cells pre- 
sent in the system. In perfusion chambers such as the "Baumgartner chamber" (5) often used to study platelet adhesion, flow is laminar and platelet attachment is primarily determined by diffusion. However, diffusion is a relatively slow process and is unlikely to account for the rapid adhesion necessary at sites of vessel wall injuries in the microcirculation (31). In our system, the maximum number of platelets that may adhere within $1 \mathrm{~s}$ to the adhesive surface due to diffusion can be calculated as $4 \pi r^{2} \lambda n_{0} N$, where $\lambda=0.6 \mu \mathrm{m}$ is the root mean square distance traveled by a platelet in $1 \mathrm{~s}$ at $37^{\circ} \mathrm{C}(32), \mathrm{r}=50 \mu \mathrm{m}$ is the average radius of a Sepharose bead, $\mathrm{n}_{0}=2.5 \times 10^{8} \mathrm{plts} / \mathrm{ml}$ is the concentration of platelets in the flow and $\mathrm{N}$ is the number of beads in the column (from 1,500 to 10,000 depending on the column size). Assuming the tightest possible packing of the beads in the column (face-centeredcubic), the corresponding adhesion rate is given by $4 \pi \mathrm{r}^{2} \lambda \mathrm{N} / \mathrm{V}_{\mathrm{f}}$, where $\mathrm{V}_{\mathrm{f}} \approx 0.26 \mathrm{~V}$ is the free volume (volume accessible to the flow) in the column and V is the total volume of the beads. This indicates that in our system the contribution of diffusion to the adhesion rate is negligible (less than $3 \%$ ) and adhesion is primarily mediated by convective transport. In this case, the rate of adhesion depends on the affinity of platelet receptors to adhesive ligands, the reactivity of the adhesive surface, and on shear forces. In this respect, our system is similar to the 'stagnation point' flow chamber, where platelet transport is perpendicular to the adhesive surface (33). This system models platelet deposition in areas of turbulent flow in blood vessels. In contrast to the stagnation point model, in our system platelets adhere to the adhesive surface forming a monolayer without aggregation, dense granule secretion, or thrombus formation. Usually, in regions where flow is disturbed and vortices and eddies can form, additional platelets interact with the adherent platelets and to each other, forming an aggregate or platelet thrombus. Due to the complex geometry of platelet flow through the tightly packed beads, it is difficult to calculate the flow parameters or to determine the areas of turbulence. By treating the system of beads as a porous medium, we previously calculated the approximate Reynolds number to be less than 1 (21). However, this does not prove that the flow is laminar, since flow disturbances may occur even at low Reynolds number in porous media. It appears that even if such disturbances take place, they are not strong enough to perturb the platelets and initiate platelet secretion, aggregation, or thrombus formation on the monolayer of adherent platelets as evidenced by scanning electron microscopy of platelets attached to the collagen-beads $(21,23)$.

It is known that the red blood cells potentiate the rate of platelet adhesion (34) and this effect has been attributed to the red cells causing an increase in concentration of platelets near the adhesive surface [up to $5-10$ fold for blood flow in the tube of diameter of $1 \mathrm{~cm}$ (35)]. It has not yet been established how platelet concentrations are affected by red cells in more complex geometries, such as in our column of tightly packed beads. We found that the presence of red cells potentiates adhesion in our microcolumn to a small degree without affecting the basic characteristics of this process. This issue is being considered more fully in ongoing work.

Despite the complex flow geometry and absence of red cells, we feel that our system provides a good model to study platelet adhesion to extracellular matrix proteins under flow conditions in microcirculation. Approximating the Sepharose-bead column as a porous medium we calculated the average diameter of the pores to be about $30 \mu \mathrm{m}(21)$, which is comparable to the diameter of capillaries and arterioles. Also the range of shear rates used in our system $\left(650-3400 \mathrm{~s}^{-1}\right)$ is similar to that of microcirculation $(31,32)$. Our system also provides the opportunity to investigate biochemical signalling in the adherent platelets (22-24).
The platelet adhesion to collagen type I, collagen type IV, and vWf (Fig. 1) exhibited a pattern of inverse exponential decay without a lag phase and can be fitted to a simple mathematical model. Let $n(t)$ denote the total number of platelets flowing through the system at time $t$, and $n_{a}(t)$ be the number of adherent platelets: $n_{a}(t)=n(0)-n(t)$. Assume that at any time the number of platelets adhering to the exposed surface within an interval $\mathrm{dt}$ is proportional to $\mathrm{n}(\mathrm{t})$. This can be described by the equation:

$\mathrm{dn} / \mathrm{dt}=-\alpha \mathrm{n}(\mathrm{t})$,

where $\alpha$ is a proportionality constant, which may depend on shear rates. Integrating this equation we obtain:

$$
\mathrm{n}_{\mathrm{a}}(\mathrm{t})=\mathrm{n}(0)(1-\exp (-\mathrm{t} / \tau))
$$

where $\tau=1 / \alpha$ is the time constant characterizing the speed of adhesion. Therefore, the adhesion rate $\mathrm{a}(\mathrm{t})=\mathrm{n}_{\mathrm{a}}(\mathrm{t}) / \mathrm{n}(0)$ is described by the inverse exponential decay:

$$
\mathrm{a}(\mathrm{t})=1-\exp (-\mathrm{t} / \tau)
$$

It follows from the Eq. [1] that the rate at which platelets are deposited on the surface is:

$$
\mathrm{dn}_{\mathrm{a}} / \mathrm{dt}=\mathrm{n}(0) / \tau-\mathrm{n}_{\mathrm{a}}(\mathrm{t}) / \tau .
$$

The first term on the right hand side may be interpreted as an association term, while the second represents a dissociation term. Eq. [4] has the same form as the equation describing platelet adhesion in stagnation point model (33), differing only in specific values of the parameters $\tau$ and $n(0)$. In fact, the inverse exponential decay kinetics may be even more universal for describing adhesion under flow conditions of various cell types in many different systems in which the basic assumption in Eq. [1] applies. However, this simple approach does not take into account possible special characteristics of adhesive surfaces or effects that may arise in systems with complicated flow geometry. In such situations, different and more complicated types of adhesion kinetics may arise. We found that kinetics of adhesion to fibrinogen and fibronectin, and laminin, deviated from the inverse exponential curve, and followed a sigmoidal pattern, with a lag phase before efficient adhesion occurred. Control substrates did not support adhesion (BSA or gelatin) or supported adhesion that had slow, non-saturable, linear kinetics (poly-1-lysine). The linear kinetics of adhesion to poly-l lysine might be explained as an effect of the electrostatic attraction between highly positively charged poly-l-lysine and negatively charged platelet membrane. As a result of this attraction, platelets acquire a constant velocity in the direction perpendicular to the bead surface. Therefore the rate of deposition of platelets on the poly-l lysine surface is constant. Denoting this rate by c, we have:

$\mathrm{dn} / \mathrm{dt}=-\mathrm{c}$

which gives linear kinetics:

$\mathrm{a}(\mathrm{t})=\mathrm{ct}$.

While adhesive proteins supported either inverse exponential decay or sigmoidal kinetics, the kinetics for the different proteins within these two categories were distinct. This suggests that rapid platelet adhesion under flow conditions to each of these proteins is specific and involves different mechanisms. For example, there is evidence that collagen may interact with the $\alpha_{2} \beta_{1}$ integrin and glycoprotein (GP) VI, as well as with other receptors (36). Immobilized-fibronectin interacts with the $\alpha_{5} \beta_{1}$ integrin, soluble fibronectin with the $\alpha_{\mathrm{IIb}} \beta_{3}$ integrin (14), laminin with the $\alpha_{6} \beta_{1}$ integrin (17), and vWf with the $\alpha_{\mathrm{IIb}} \beta_{3}$ integrin 
and the GPIb-IX complex (2). Both receptor surface density and affinity for the substrate protein will strongly influence platelet adhesion efficiency.

Varying shear rates also affected kinetics of adhesion (Fig. 1 and Table 1). Adhesion to collagens type I and IV was independent of shear rates in the range of 650-3400 $\mathrm{s}^{-1}$. These findings are in a good agreement with previous observation that these collagens supported adhesion in shear rate independent manner from 300 to $1600 \mathrm{~s}^{-1}$ (12). Similarly, adhesion to vWf and fibronectin was independent of shear rates from 650 to $3400 \mathrm{~s}^{-1}$, while adhesion to laminin and fibrinogen was more efficient at low shear rates $\left(650-1000 \mathrm{~s}^{-1}\right)$. These results agree with reports showing that adhesion to laminin and fibrinogen is more efficient at low shear rates $\left(<1000 \mathrm{~s}^{-1}\right)$ than at high shear rates (16-20). Several studies indicate that adhesion to vWf is shear rate dependent and much more efficient at high shear rate $\left(>800 \mathrm{~s}^{-1}\right)(13)$. However, in these studies adhesion was observed on the timescale of minutes and involved thrombus formation. In our microadhesion assay there is no thrombus formation as evidenced by scanning electron microscopy $(21,23)$. Thus, our findings agree with the proposal that initial adhesion of platelets to $\mathrm{vWf}$ is shear rate independent (13).

It is well known that platelet adhesion to ECM proteins strongly depends on the presence of divalent cations $(16,17,21,37,38)$. In the present study platelets were resuspended in ACD-plasma. Such plasma has decreased physiological concentrations of $\mathrm{Ca}^{2+}(\leq 50 \mu \mathrm{M})$ and $\mathrm{Mg}^{2+}$ $(\leq 100 \mu \mathrm{M})$, which may affect adhesion efficiency and rate. Previously, we have observed that in heparin- or hirudin-prepared plasma, where physiological concentrations of divalent cations are present, adhesion to collagen type I is faster than in ACD-plasma (21). Similarly, it has been reported that the total extent and shear rate dependence of platelet adhesion to laminin are significantly influenced by changing the concentrations of divalent cations (17). Nevertheless, in our system adhesion is rapid and efficient even at lower than physiological concentrations of $\mathrm{Ca}^{2+}$ and $\mathrm{Mg}^{2+}$.

Four of the adhesive proteins we used were of human origin (collagen type IV, fibronectin, fibrinogen, von Willebrand Factor), while laminin and collagen type I were of animal origin. Laminin was purified from mouse tumors and collagen type I was from rat skin. Laminin isolated from the mouse tumor matrix is the most available form of laminin, and is found in various tissues such as skin and blood vessel. An important consideration when studying platelet interaction with laminin is that there are multiple forms of this ubiquitous protein. Platelets possess the $\alpha_{6} \beta_{1}$ integrin which serve as receptor for laminin (39) and it is well established that efficiency of platelet binding to immobilized mouse and human laminin is similar and mediated by the $\alpha_{6} \beta_{1}$ integrin (40). Therefore, we would expect similar adhesion characteristics for these two forms of laminin. Nevertheless, it is possible that platelets may interact differently with each laminin isoform, since there are indications that there may be species-specific differences in the structural and biological properties of each laminin type. In contrast, collagens are highly conserved proteins and there are no indications in the literature of major differences in the structure or biological activity of human and rat collagen type I.

Our results suggest several interesting topics for the future research. It would be important to characterize fully the platelet receptors that mediate adherence to each of the proteins tested using the physiologically relevant shear rates and contact times provided by our assay. Antibodies or short peptides that block particular adhesion receptors could be included in our assay to identify the platelet receptors involved in adhesion to particular proteins. For example, there is evidence that several platelet receptors cooperate to mediate platelet adhesion to collagen in plasma $(21,41)$. The relative involvement of different receptors under low versus high shear conditions is important, and in addition, some receptors may be considered to serve more as signaling receptors than as primary adhesive receptors.

Concomitantly, possible platelet receptor binding sites within particular proteins can be identified and it would be interesting to couple peptides or protein fragments that contain these sites to Sepharose beads to determine if they mediate the rapid platelet adhesion observed here (42). In addition, the effect of soluble modulators of platelet function (thrombin, ADP, epinephrine or $\mathrm{PGI}_{2}$ ) on platelet adhesion in our assay would be interesting to characterize.

An important and useful aspect of our experimental approach is that it enables study of signaling events in platelets that have actually adhered to substrate proteins under shear conditions. We have recently shown that platelet adhesion to rat skin collagen type I elicits activation of protein phosphatases, including dissociation of a large protein complex consisting of heat shock proteins and protein phosphatases (24). Whether platelet binding to other proteins will initiate similar signal transduction events will be intriguing to learn.

In conclusion, the present study demonstrates the ability of human platelets to efficiently adhere to several ECM proteins and to fibrinogen under physiologically relevant shear conditions and exposure times (seconds) in ACD-plasma without red cells. Platelet adhesion to each protein displayed unique kinetics and, in some cases, was dependent on shear rate suggesting that platelets use different mechanisms to adhere to each protein tested. We show for the first time that platelets are able to specifically adhere to collagens type I and IV, vWF, fibronectin, laminin, and fibrinogen within seconds, a timescale necessary to maintain efficient haemostasis in arterial circulation.

\section{Acknowledgements}

We thank Xiaomei Li for technical assistance; Dr. Gary Balian, Dr. Roy Ogle, and Dr. Zaverio Ruggeri for gifts of collagen, laminin, and vWF, respectively; and Dr. Marek Grabowski for helpful discussion concerning our flow model. This work was supported by the Carman Trust and by NIH (HL-27014) for some of the original equipment.

\section{References}

1. Hawiger J. Mechanisms involved in platelet vessel wall interaction. Thromb Haemost 1995; 74: 369-72.

2. Ruggeri ZM. Mechanisms initiating platelet thrombus formation. Thromb Haemost 1997; 78: 611-6.

3. Born GVR, Richardson PD. Activation time of blood platelets. J Membr Biol 1980; 57: 87-90.

4. Born GVR, Kratzer MAA. Source and concentration of extracellular adenosine triphosphate during haemostasis in rats, rabbits and man. J Physiol (London) 1984; 354: 419-29.

5. Baumgartner HR. Platelet interaction with collagen fibrils in flowing blood. I. Reaction of human platelets with alpha chymotrypsin-digested subendothelium. Thromb Haemost 1977; 37: 1-16.

6. Muggli R, Baumgartner HR, Tschopp TB, Keller H. Automated microdensitometry and protein assays as a measure for platelet adhesion and aggregation on collagen-coated slides under controlled flow conditions. J Lab Clin Med 1980; 95: 195-207.

7. Sakariassen KS, Aarts PA, de Groot PG, Houdijk WP, Sixma JJ. A perfusion chamber developed to investigate platelet interaction in flowing blood with human vessel wall cells, their extracellular matrix, and purified components. J Lab Clin Med 1983; 102: 522-35.

8. Aihara M, Cooper HA, Wagner RH. A quantitative method for studying platelet adhesion to collagen. J Lab Clin Med 1984; 103: 758-67. 
9. Smith JB, Dangelmaier C. Determination of platelet adhesion to collagen and the associated formation of phosphatidic acid and calcium mobilization. Anal Biochem 1990; 187: 173-8.

10. Sixma JJ, van Zanten GH, Banga JD, Nieuwenhuis HK, de Groot PG. Platelet adhesion. Semin Hemat 1995; 32: 1-6.

11. Sixma JJ, van Zanten GH, Saelman EUM, Verkleij M, Lankhof H, Nieuwenhuis K, de Groot PG. Platelet adhesion to collagen. Thromb Haemost 1995; 74: 454-9.

12. Saelman EU, Nieuwenhuis HK, Hese KM, de Groot PG, Heijnen HF, Sage EH, Williams S, McKeown L, Gralnick HR, Sixma JJ. Platelet adhesion to collagen types I through VIII under conditions of stasis and flow is mediated by GPIa/IIa ( $\alpha_{2} \beta_{1}$-integrin). Blood $1994 ; 83$ : 1244-50.

13. Ruggeri ZM. Mechanisms of shear-induced platelet adhesion and aggregation. Thromb Haemost 1993; 70: 119-23.

14. Piotrowicz RS, Orchekowski RP, Nugent DJ, Yamada KY, Kunicki TJ. Glycoprotein Ic-IIa functions as an activation-independent fibronectin receptor on human platelets. J Cell Biol 1988; 106: 1359-64.

15. Tandon NN, Holland EA, Kralisz U, Kleinman HK, Robey FA, Jamieson GA. Interaction of human platelets with laminin and identification of the $67 \mathrm{kDa}$ laminin receptor on platelets. Biochem J 1991; 274: 535-42.

16. Beumer S, Ijsseldijk JW, de Groot PG, Sixma JJ. Platelet adhesion to fibronectin in flow: dependence on surface concentration and shear rate, role of platelet membrane glycoproteins GP IIb/IIIa and VLA-5, and inhibition by heparin. Blood 1994; 84: 3724-33.

17. Hindriks G, IJssildijk MJW, Sonnenberg A, Sixma JJ, de Groot PG. Platelet adhesion to laminin: role of $\mathrm{Ca}^{+2}$ and $\mathrm{Mg}^{+2}$ Ions, shear rate, and platelet membrane glycoproteins. Blood 1992; 79: 928-35.

18. Endenburg SC, Hantgan RR, Sixma JJ, de Groot PG, Zwaginga JJ. Platelett adhesion to fibrin(ogen). Blood Coagulat Fibrynol 1993; 4: 139-42.

19. Savage B, Saldivar E, Ruggeri ZM. Initiation of platelet adhesion by arrest onto fibrinogen or translocation on von Willebrand Factor. Cell 1996; 84: 289-97.

20 Zaidi TN, McIntire LV, Farrell DH, Thiagarajan P. Adhesion of platelets to surface-bound fibrinogen under flow. Blood 1996; 88: 2967-72.

21. Polanowska-Grabowska R, Gear ARL. High-speed platelet adhesion under conditions of rapid flow. Proc Natl Acad Sci 1992; 89: 5754-8.

22. Polanowska-Grabowska R, Gear ARL. Role of cyclic nucleotides in rapid platelet adhesion to collagen. Blood 1994; 83: 2508-15.

23. Polanowska-Grabowska R, Geanacopoulos M, Gear ARL. Platelet adhesion to collagen via the $\alpha_{2} \beta_{1}$ integrin under arterial flow conditions causes rapid tyrosine phosphorylation of pp125 ${ }^{\mathrm{FAK}}$. Biochem J 1993; 296: 543-7.

24. Polanowska-Grabowska R, Simon, Jr CG, Falchetto R, Shabanowitz J, Hunt DF, Gear ARL. Platelet adhesion to collagen under flow causes dissociation of a phosphoprotein complex of heat-shock proteins and protein phosphatase 1. Blood 1997; 90: 1516-26.

25. Ruoslahti E, Hayman EG, Peirschbacher M, Engvall E. Fibronectin: purification, immunochemical properties, and biological activities. Methods Enzymol 1982; 82: 803-31.

26. Ruggeri ZM, de Marco L, Gatti L, Bader R, Montgomery RR. Platelets have more than one binding site for von Willebrand factor. J Clin Invest 1983; 72: 1-12.
27. Davis LA, Ogle RC, Little CD. Embryonic heart mesenchymal cell migration in laminin. Dev Biol 1989; 133: 37-43.

28. Cuatrecasas P. Protein purification by affinity chromatography. Derivitizations of agarose and polyacrylamide beads. J Biol Chem 1970; 245: 3059-65.

29. Lowry OH, Rosebrough NJ, Farr AL, Randall RJ. Protein measurement with the Folin phenol reagent. J Biol Chem 1951; 193: 265-75.

30. Gear ARL. Rapid reactions of platelets studied by a quenched-flow approach: aggregation kinetics. J Lab Clin Med 1982; 100: 866-86.

31. Slack SM, Cui Y, Turitto VT. The effects of flow on blood coagulation and thrombosis. Thromb Haemost 1993; 70: 129-34.

32. Goldsmith HL, Turitto VT. Rheological aspects of thrombosis and haemostasis: Basic principles and applications. Thromb Haemost 1986; 55: 415-35.

33. Tippe A, Reininger A, Reininger C, Rieß R. A method for quantitative determination of flow induced human platelet adhesion and aggregation. Thromb Res 1992; 67: 407-18.

34. Aarts PAMM, van den Broek SAT, Prins GW, Kuiken GDC, Sixma JJ, Heethaar RM. Blood platelets are concentrated near the vessel wall and red blood cells in the center in flowing blood. Arteriosclerosis 1988; 8: 819-24.

35. Eckstein EC, Tilles AW, Millero FJ. Conditions for the occurrence of large near wall excesses of small particles during blood flow. Microvasc Res 1988; 36: 31-39.

36. Moroi M, Jung SM. Platelet receptors for collagen. Thromb Haemost 1997; 78: 439-44.

37. van Zanten H, Saelman EU, Schut-Hese KM, Wu YP, Slootweg PJ, Nieuwenhuis HK, de Groot PG, Sixma JJ. Platelet adhesion to collagen type IV under flow conditions. Blood 1996; 88: 3862-71.

38. Staatz WD, Rajpara SM, Wayner EA, Carter WG, Santoro SA. The membrane glycoprotein Ia-IIa (VLA-2) complex mediates the $\mathrm{Mg}^{++}$-dependent adhesion of platelets to collagen. J Cell Biol 1989; 108: 1917-24.

39. Sonnenberg A, Modderman PW, Hogervorst F. Laminin receptor on platelets is the integrin VLA-6. Nature 1988; 336: 487-9.

40. Sonnenberg A, Gehlsen KR, Aumailley M, Timpl R. Isolation of $\alpha_{6} \beta_{1}$ integrins from platelets and adherent cells by affinity chromatography on mouse laminin fragment E8 and human laminin pepsin fragment. Exp Cell Res 1991; 197: 234-44.

41. Coller BS, Beer JH, Scudder LE, Steinberg MH. Collagen-platelet interactions: evidence for a direct interaction of collagen with platelet GPIa/IIa and an indirect interaction with platelet GPIIb/IIIa mediated by adhesive proteins. Blood 1989; 74: 182-92.

42. Barnes MJ, Knight CG, Farndale RW. The use of collagen-based model peptides to investigate platelet-reactive sequences in collagen. Biopolymers 1996; 40: 383-97.

Received March 24, 1998 Accepted after resubmission September 23, 1998 